http://jmscr.igmpublication.org/home/ ISSN (e)-2347-176x ISSN (p) 2455-0450

crossref DOI: https://dx.doi.org/10.18535/jmscr/v8i2.102

\title{
A Retrospective Study on the Incidence of Carcinoma Stomach in Tertiary Care Hospital
}

\author{
Authors \\ Dr A V V Siva Prasad ${ }^{1}$, Dr D Narendra ${ }^{2 *}$, Dr Rohini $D^{3}$, Dr Akhila $V^{4}$ \\ ${ }^{1,2,3,4}$ Post Graduate, General Surgery, Andhra medical college ,Visakhapatnam \\ *Corresponding Author \\ Dr D Narendra Babu \\ Post Graduate, General Surgery, Andhra Medical College, Visakhapatnam, India
}

\begin{abstract}
Introduction: Adenocarcinoma of the stomach was the second leading cause of cancer-related deaths worldwide ${ }^{l}$. Gastric cancer is actually an eminently curable disease provided that it is detected at an appropriate stage and treated adequately.

Materials and Methods: This study was a retrospective study. Forty patients came to the surgical department with GI-related symptoms, diagnosed and histopathologically proven to have adenocarcinoma stomach.

Results: Out of 40 patients, 22 patients presented with carcinoma stomach between the age of 45-65 years, 29 patients were male. Out of 40 patients, 34 patients belong to the low socioeconomic group. Thirty-five patients had a history of intake of spicy food, and 25 patients had alcohol intake and19 patients had a smoking history.

Conclusion: Carcinoma Stomach is more common in males and more common in the older age group. Mostly in the low socioeconomic group. Smoking is clearly an important risk factor, and the risk increases if it was associated with alcohol intake. The most common presenting symptoms were anorexia, nausea and vomiting, and weight loss.

Keywords: Gastric Cancer, Epidemiology, Adenocarcinoma of the stomach, Jaundice.
\end{abstract}

\section{Introduction}

In most countries, the annual standardized incidence of new cases is 8 to 20 per 100,000 population, with an overall 5year survival rate of about $16 \%$. In India, more than $98 \%$ of all gastric cancers are diagnosed at an advanced stage, and in those subjected to surgery, more than $70 \%$ have serosal infiltration. Stomach cancer admissions in south India are four times as frequent as in north India with a remarkable preponderance of males ${ }^{2}$ (20:1) versus (7:1) in the rest of India. The disease is seen most frequently between the ages 50-70 years with a peak age of about 60 for both sexes. Gastric cancer is rare under 30 years of age. Carcinoma of the distal stomach is most common in low socioeconomic groups, whereas the increase in proximal cancer seems to affect principally higher socioeconomic groups. High salt and nitrate consumption associated with carcinoma stomach ${ }^{3}$, conversely, the consumption of raw vegetables, citrus fruits, and high fiber diet associated with the lowered risk ${ }^{4}$. 


\section{Materials and Methods}

The present study was a retrospective study for a period of 2 years., from September 2017 to October 2019. This study was a retrospective study. Forty patients came to the surgical department with GI-related symptoms, diagnosed and histopathologically proven to have adenocarcinoma stomach. Various variables like incidence, sex, age at presentation, symptom wise incidence, related risk factors were compared and studied.

\section{Statistical Analysis}

SPSS version 21 was used for generating tables and graphs. Results are based on descriptive statistics.

\section{Results}

In this study maximum number of cases was seen between the age groups of 45-65. The youngest patient was aged 35 and the oldest 82 years.

\begin{tabular}{|l|c|c|c|c|}
\hline Age & Total & Percentage & Male & Female \\
\hline $35-44$ & 7 & 17.5 & 4 & 2 \\
\hline $45-54$ & 11 & 27.5 & 7 & 4 \\
\hline $55-64$ & 11 & 27.5 & 9 & 2 \\
\hline $65-74$ & 8 & 20 & 7 & 2 \\
\hline$>75$ & 3 & 7.5 & 2 & 1 \\
\hline
\end{tabular}

In this study, Gastric cancer is more common in males, with $72.5 \%$ of the cases being males. The male to female ratio of $2.6: 1$

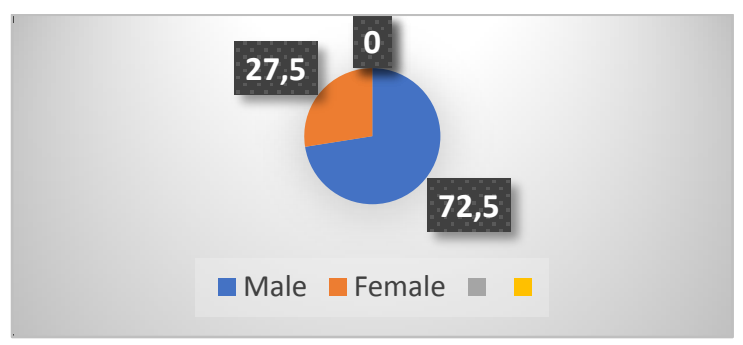

In this study majority of the patients belonged to the low socioeconomic status ( $85 \%)$.

The most common risk factors associated were spicy smoked food, followed by tobacco and alcohol use. Smoked food though a common risk factor in many countries, was consumed only by 4 $(10 \%)$ of the patients, and even in these patients, the intake was not frequent. The majority of the patients,35 $(87.5 \%)$ reported using of high spicy diet in everyday food. Tobacco smoking in the form of cigarette and beedi smoking was seen in $19(47.5 \%)$ patients, all being males. Alcohol consumption was seen in $25(62.5 \%)$ patients, all males, who consumed it regularly and for a period of more than ten years. The relationship of gastric cancer with Helicobacter pylori couldn't be assessed in this study.

\begin{tabular}{|l|c|c|c|}
\hline Risk factors & $\begin{array}{c}\text { Total } \\
\text { cases }\end{array}$ & Males(29) & Females(11) \\
\hline High salt intake & 0 & 0 & 0 \\
\hline Smoked food & 4 & 2 & 2 \\
\hline Spicy food & 35 & 27 & 9 \\
\hline Smoking & 19 & 19 & 0 \\
\hline Alcohol & 25 & 25 & 0 \\
\hline Hereditary & 0 & 0 & 0 \\
\hline $\begin{array}{l}\text { Prior Gastric } \\
\text { Surgery }\end{array}$ & 1 & 3 & 0 \\
\hline
\end{tabular}

Anorexia was the most common symptom in patients and was reported $32(80 \%)$ of the patients. The next most common symptom was nausea and vomiting seen in thirty (75\%) patients reflecting the high prevalence of distal tumors. 29(72.5\%) patients reported significant weight loss. Proximal tumors involving the gastroesophageal junction had dysphagia as the predominant symptom. It was seen in $4(10 \%)$ patients. Only $2(5 \%)$ patients in the study presented with jaundice and one $(2.5 \%)$ patient had left supraclavicular lymphadenopathy at presentation. One (2.5\%) patient presented with features of peritonitis and was found to have a growth in the antrum of the stomach, which had perforated. Early satiety was reported in five $(12.5 \%)$ of the patients. Pain abdomen was seen in 28(70\%) patients and melaena in $7(17.5 \%)$ patients

\begin{tabular}{|l|l|l|l|}
\hline Symptom & Total Cases & Males & Females \\
\hline Anorexia & 32 & 21 & 11 \\
\hline Nausea and vomithing & 30 & 22 & 8 \\
\hline Weight loss & 29 & 18 & 11 \\
\hline Pain abdomen & 28 & 19 & 9 \\
\hline Malaena & 7 & 5 & 2 \\
\hline Early satiety & 5 & 4 & 1 \\
\hline Dysphagia & 4 & 3 & 1 \\
\hline Jaundice & 2 & 2 & 0 \\
\hline Peritonitis & 1 & 1 & 0 \\
\hline
\end{tabular}




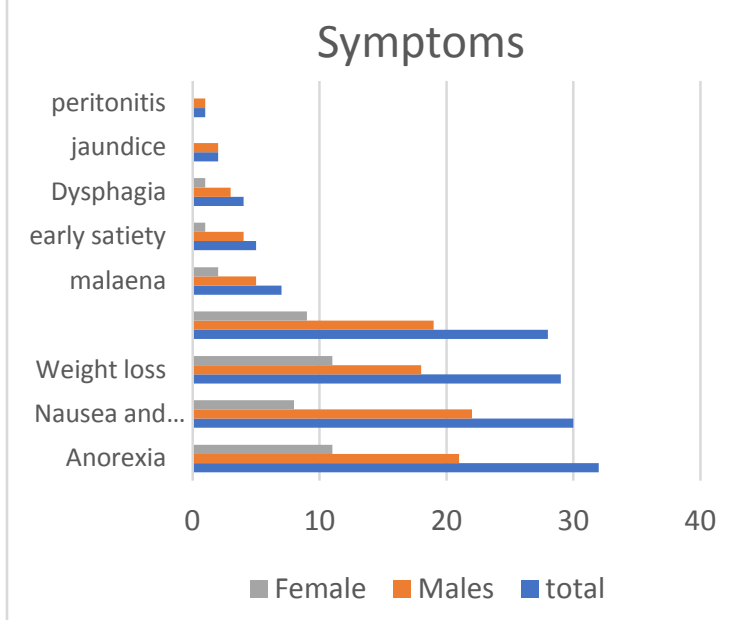

\section{Discussion}

In this study maximum number of cases was seen after the age of 45 years. Urmi sen et $\mathrm{al}^{5}$. studied cancer patterns in eastern India also noted a similar age trend with the increasing incidence of gastric cancer with age. In this study, the youngest patient was aged 35 and the oldest 82 years. In a study by Rajkumar et al., 2010,16 patients were aged more than 45 years, and 8 were 45 years or less ${ }^{6}$. Gastric cancer was more common in males, with the global age-standardized incidence for males about 2.2 times higher than for females. Males had a higher incidence in all regions. Men have greater exposure to one or more environmental carcinogens and so are more susceptible. Similar observations were made in this study with M: F ratio 2.6:1. Rajkumar et al. studied 24 patients of gastric carcinoma, out of which 18 were males, and 6 were females.

\begin{tabular}{|l|c|c|c|c|}
\hline Sex & \multicolumn{2}{|c|}{ Sumathi et al. 2009 } & \multicolumn{2}{c|}{ Present study } \\
\hline & Cases & $\%$ & Cases & $\%$ \\
\hline Male & 64 & 71.9 & 29 & 72.5 \\
\hline Female & 25 & 28.1 & 11 & 27.5 \\
\hline
\end{tabular}

The majority of the cases in this belongs to low socioeconomic status accounting for $85 \%$. The scenario is similar across India, where the majority of the population belongs to the low socioeconomic group, further contributing evidence of the dietary role of carcinogens.

\begin{tabular}{|l|c|c|c|c|}
\hline \multirow{2}{*}{$\begin{array}{l}\text { Socio } \\
\text { economic } \\
\text { group }\end{array}$} & \multicolumn{2}{|c|}{$\begin{array}{l}\text { Sumathi et al } \\
2009^{7}\end{array}$} & \multicolumn{2}{c|}{ Present study } \\
\cline { 2 - 5 } & Cases & $\%$ & Cases & $\%$ \\
\hline Low & 59 & 66.3 & 34 & 85 \\
\hline Medium & 27 & 30.3 & 6 & 15 \\
\hline High & 03 & 3.37 & 0 & 0 \\
\hline
\end{tabular}

The association of tobacco use and alcohol has been studied. In this Study 19(47.5\%) patients reported the use of smoking for a significant period compared to $40.5 \%$ in the study by Sumathi et al. In another study, a high consumption of rice with chilly and the consumption of high-temperature foods were (7 fold increased risk) found to be independent risk factors.

Abdominal pain was a major symptom-related in $28(70 \%)$ of the cases compared to $56,6 \%$ in a study by Safaee et al. Weight loss was seen in 29 cases $(72.5 \%)$ compared to $57.7 \%$ cases.

\begin{tabular}{|l|c|c|c|c|}
\hline Symptoms & \multicolumn{2}{|c|}{ Safaee et al $2009^{8}$} & \multicolumn{2}{c|}{ Present study } \\
\hline Anorexia & Cases & $\%$ & Cases & $\%$ \\
\hline $\begin{array}{l}\text { Nausea and } \\
\text { vomithings }\end{array}$ & 324 & 43.2 & 30 & 75 \\
\hline Weight loss & 434 & 57.7 & 29 & 72.5 \\
\hline Pain abdomen & 425 & 56.6 & 28 & 70 \\
\hline Malaena & 144 & 19.1 & 7 & 17.5 \\
\hline Early satiety & 263 & 31.5 & 5 & 12.5 \\
\hline Dysphagia & 263 & 31.5 & 4 & 10 \\
\hline Jaundice & 0 & 0 & 2 & 5 \\
\hline Peritonitis & 0 & 0 & 1 & 2.5 \\
\hline
\end{tabular}

\section{Conclusion}

In this study on the incidence of carcinoma stomach, there is a male predominance and is more common in the older age group. Incidence is more in patients belonging to the low socioeconomic group. Smoking clearly is an important risk factor in the development of gastric cancers. If it is associated with alcohol intake, also, cancer risk increased. The most common presenting symptoms for distal gastric cancers were vomiting, loss of appetite, and loss of weight and pain abdomen.

\section{References}

1. Parkin DM, Bray FI, Devesa SS. Cancer burden in the year 2000. The global 
picture. European journal of cancer. 2001

Sep 1;37:4-66.

2. El-Serag HB, Mason AC, Petersen N, Key

CR. Epidemiological differences between adenocarcinoma of the esophagus and adenocarcinoma of the gastric cardia in the USA. Gut. 2002 Mar 1;50(3):368-72.

3. Takahashi M, Hasegawa R. Enhancing effects of dietary salt on both initiation and promotion stages of rat gastric carcinogenesis. Princess Takamatsu Symposia 1985 (Vol. 16, pp. 169-182).

4. Kobayashi M, Tsubono Y, Sasazuki S, Sasaki S, Tsugane S, JPHC Study Group. Vegetables, fruit, and risk of gastric cancer in Japan: a 10- year follow- up of the JPHC Study Cohort I. International journal of cancer. 2002 Nov 1;102(1):39-44.

5. Sen U, Sankaranarayanan R, Mandal S, Ramanakumar AV, Parkin DM, Siddiqi M. Cancer patterns in eastern India: the first report of the Kolkata cancer registry. International journal of cancer. $2002 \mathrm{Jul}$ 1;100(1):86-91.

6. Rajkumar T, Vijayalakshmi N, Gopal G, Sabitha K, Shirley S, Raja UM, Ramakrishnan SA. Identification and validation of genes involved in gastric tumorigenesis. Cancer cell international. 2010 Dec 1;10(1):45.

7. Sumathi B, Ramalingam S, Navaneethan U, Jayanthi V. Risk factors for gastric cancer in South India. Singapore medical journal. 2009 Feb 1;50(2):147.

8. Pourhoseingholi MA, Moghimi-Dehkordi B, Safaee A, Hajizadeh E, Solhpour A, Zali MR. Prognostic factors in gastric cancer using a log-normal censored regression model. Indian Journal of Medical Research. 2009 Mar 1;129 (3):262. 